\title{
THE ROLE OF SPELLING IN LEARNING TO READ.
}

\section{Nick Ellis and Suzanne Cataldo}

\author{
Department of Psychology, \\ University College of North Wales, \\ Bangor, Gwynedd, Wales
}

Correspondence to Nick Ellis, U.C.N.W

\author{
Keywords: \\ Spelling Reading Phonological Awareness \\ Longitudinal Study Spelling Errors Reading Teaching
}

Submitted to Language and Education 


\begin{abstract}
Early interactive processes of development in reading, spelling and implicit and explicit phonological awareness were assessed in a group of children at four time-points as they progressed through their first three years in school. Exploratory causal path analyses were used to investigate the contribution of each ability to the subsequent growth of skill in reading, spelling and phonological awareness. The resultant structural models demonstrate a role of spelling in the early stages of reading acquisition, as well as differential contributions of implicit and explicit phonological awareness to both reading and spelling. They also suggest a developmental cascade from implicit to explicit phonemic awareness in the normal acquisition of phonological knowledge and associated skills. An analysis of the children's spelling errors at these stages demonstrates that spelling changes in nature from being precommunicative, through semi-phonetic to phonetic in nature, and these changes are associated with the children's increasing explicit phonological awareness.

In the early formulative stages of reading, implicit phonemic awareness and reading act reciprocally to build skill in each other. But, as ability in word recognition improves, implicit phonemic awareness plays a diminished role in reading. This pattern of initial reciprocal influence and later dissociation is repeated in the relationship between implicit phoneme awareness and spelling. Explicit phonemic awareness is an important factor in the first stages of spelling development but only emerges later as a significant contributor to reading. The early influence of explicit phoneme awareness on spelling, in conjunction with the major contribution of spelling to beginning reading, indicates that experience in spelling promotes the use of a phonological strategy in reading. Within a developmental context, explicit phoneme awareness initially appears to grow out of an implicit appreciation of the overall sound properties of words. Thereafter, ability to identify and segment phonemes develops independently of implicit phonemic awareness and plays an increasingly important role in the further growth of reading and spelling.

The implications of these findings for teaching are clear: the teaching of spelling and phonological awareness is an integral and important part of early reading instruction.
\end{abstract}




\section{INTRODUCTION}

Although the importance of phonological awareness (PA) in the acquisition of reading has been established (Bradley and Bryant, 1983; Ellis and Large, 1987, 1988; Frith, 1985) the causal pathways between the two abilities have eluded clear determination (Bryant and Goswami, 1987; Shanahan and Lomax, 1986) since there are many and various factors which might influence studies of the co-development of phonological awareness and reading, viz., (i) the range of phonological awareness skills tapped by different tasks (Lewkowicz, 1980; Ellis and Large, 1988; Stanovich, Cunningham and Cramer 1984), (ii) the range of different types of reading tapped by different reading tasks and the child's ability to relate sound to graphic information (Lomax and McGee, 1987), (iii) short term and working memory (Ellis, 1989), and (iv) different methods of reading instruction ( Morais, Cary, Alegria and Bertelson, 1979; Alegria, Pignot and Morais 1982). Furthermore, research that examines the relationship of phonological awareness to the emergence of literacy has often neglected spelling as an important agent that independently influences and is influenced by phonological awareness and reading. Whilst it has been acknowledged that use of a phonological strategy plays a fundamental role in spelling before it becomes important in reading (Smith, 1973; Bryant and Bradley, 1980; Frith, 1980; Snowling and Perin, 1983; Juel, Griffith and Gough 1986), comparatively little attention has been focused on the possible routes of interaction among reading, spelling and phonological skills. Correlational studies provide evidence of a strong relationship between early reading and spelling and between spelling and phoneme awareness (Snowling and Perin, 1983; Juel, Griffith and Gough 1986; Ellis and Large, 1987). However, the form of causal connections cannot be determined from correlations alone.

There are some recent correlational and longitudinal studies which now identify spelling as an independent contributor to the emergence of reading (Morris and Perney; 1984; Tornéus, 1984; Mommers, 1987; Cataldo and Ellis, 1988), and these support theoretical analyses that assign spelling the major role in promoting insight into the alphabetic nature of the written language (Bryant and Bradley, 1980; Frith, 1985; Juel, Griffith and Gough, 1986). Spelling is a necessary component in a complete theory of early literacy acquisition. 
The use of phonological awareness in children's early efforts in spelling encourages them to approach the printed word as a sequence of phonetic cues to pronunciation (Liberman and Shankweiler, 1979; Frith, 1985). As children refine their ability to detect and isolate the sound content of spoken words through repeated practice in spelling, so they build a store of knowledge about the relationships among sounds, letters and pronunciations that can be applied to the task of reading (Chomsky, 1977; Ehri and Wilce, 1987; Juel, Griffith and Gough, 1986). Ehri and Wilce (1987) explored the idea that spelling may help children to read. They taught kindergarten children to spell words by attending to constituent lettersound sequences, and when necessary, to phonetic, phonemic and articulatory cues. These children learned to read words better than children who were taught isolated letter-sound relationships. Thus children trained in spelling were superior to the controls in their ability to use phonetic cues and letter-sound constituents when learning to read words. Ehri and Wilce propose that beginners approach spelling in a similar manner to reading, in both tasks they rely on a store of associations between letter-name knowledge and word pronunciations and thus spelling words helps children detect and utilize phonetic cues in the printed word. Phonetic-cue reading begins when the learner first makes associations between a salient letter (or letters) in the printed word and corresponding sounds in the spoken word. According the Ehri and Wilce, this nascent sound strategy of using partial phonetic cues is formed during early reading experience. At some later point the learner develops a highly systematic and efficient strategy of decoding the printed word, a new ability which has been described as 'deciphering' (Gough and Hillinger, 1980), 'sequential decoding' (Marsh, Friedman, Welch and Desberg, 1981), 'alphabetic-stage' reading (Frith, 1985), and 'phonological-recoding' (Harris and Coltheart, 1986). If we neglect to include spelling in the configuration of factors promoting alphabetic-stage reading, we fail to recognize an important source of knowledge that helps elucidate the relationship between printed words and their pronunciations, since it is practice in spelling that enhances the knowledge base from which novice readers draw information in their attempts at phonetic-cue and cipher reading.

Frith (1985) provides a theoretical framework within which spelling and reading interact to 
advance the learner towards increased proficiency in each ability. In her model, spelling plays a fundamental role in the movement from a visual, or logographic reading strategy to alphabetic approach: alphabetic spelling is the pacemaker for the use of an alphabetic strategy in reading. If we consider phonetic-cue reading as a pre-alphabetic strategy, we see children moving from the use of visual features (Gough and Hillinger, 1980; Marsh, Friedman, Welch and Desberg, 1981; Seymour and Elder, 1985) and partial phonetic cues (Ehri and Wilce, 1987) to the use of deciphering or 'cipher' reading (Gough and Hillinger, 1980). Early spelling practice typically involves dividing spoken words into phonemes and representing these phonemes with letters. In this way experience in spelling words affords the opportunity for making comparisons between the phonetic information in individual letters and sounds as they are embedded in the spoken word. Spelling practice helps to establish this abstract concept through two very concrete means; articulatory and kinesthetic rehearsal. Through repeated practice in spelling, the child may come to appreciate the subtle relationship between a symbol in the written word and its corresponding sound in the context of the spoken word. The discovery of this relationship is the key to alphabetic insight. The crux of the problem is 'knowing how to combine the letters into units appropriate for speech' (Liberman and Shankweiler, 1979 p. 141). Early efforts in spelling may provide the opportunity to experiment in a very concrete way with the properties of this abstract concept. As children struggle to decompose words into individual phonemic units, they commonly experiment with various articulatory rehearsals of word parts and they search for distinguishable articulatory units that correspond to letter-sound units. This process of their separating sounds in a word through consciously monitoring their own articulations may serve a dual purpose: it may both help the development of phonological awareness and enhance knowledge of the alphabetic principle.

The idea that explicit and productive knowledge of the sound content of words comes to reading via spelling may account for the power of spelling to predict reading in recent studies (Shanahan and Lomax, 1986; Mommers,1987; Ellis and Large, 1988; Cataldo and Ellis, 1988; Ellis and Large, 1987). These studies reveal the previously hidden role that spelling plays in the child's first steps towards literacy. But now we need a broader and 
more detailed description of the interactive development of all three components, reading, spelling, and phonological awareness, in order to clarify the details of precisely how spelling mediates the influence of phonological awareness on reading. In terms of educational practice it is vital to explore how the early development of spelling and phonological awareness help children across the threshold to literacy.

\section{A LONGITUDINAL STUDY OF THE DEVELOPMENT OF SPELLING, READING AND PHONOLOGICAL AWARENESS}

In our recent longitudinal study (Cataldo and Ellis, 1988) we examined the growth of reading, spelling, and phonological awareness, from the formulative stage of each skill through the early stages of its development. We followed a group of children as they progressed through the earliest stages of literacy acquisition. By charting their development in spelling, reading and phonological awareness, we were able to analyse the factors which contribute to the early formation of these skills as well as the sequences of interaction which facilitate later strategy shifts in each ability.

\section{Method}

\section{Subjects}

Forty children were selected from three schools in North Wales. At the beginning of the study, the children were attending either reception or infant classes. The children were English speaking and were taught reading and spelling in English. Initial testing commenced in the autumn of 1985 when the children were between 4 and 5 years old. At this time most of the children did not demonstrate even rudimentary skill in reading or spelling. The children were assessed on three subsequent occasions; once when most were at the end of their first year in school, again in the autumn of their second year and finally at the beginning of their third school year. By the final testing time, 28 subjects had taken the full complement of tests, and it is the performance of these children which is used in the following LISREL analyses.

\section{Procedure}

Children between 4 and 5 years old were tested individually in reading, spelling, phoneme 
segmentation, auditory categorization, letter-sound knowledge, STM and full WPPSI IQ (Wechsler, 1967; Saville, 1971). Tests of reading, spelling and phonological awareness were repeated when most of the children were finishing their first year at school. The full set of tests (excluding the WPPSI) was readministered the following autumn. One year later, when the majority of the children were beginning their third school year, a final administration of the reading and spelling tests was given. In order to compare performances in very different areas, test scores were converted to stanine scores; this standardizes the means and variances of each variable and normalizes the data in accord with the assumptions of LISREL causal modeling. Each of the tests, testing procedures and scoring methods is described below. For a more detailed description of procedures see Cataldo and Ellis, 1988.

\section{$\underline{\text { TESTS }} \underline{\text { OF READING }} \underline{\text { AND }} \underline{\text { SPELLING }}$}

The reading and spelling tests consisted of phonemically regular, consonant-vowelconsonant $(\mathrm{C}-\mathrm{V}-\mathrm{C})$ words. All words contained short vowels.

(C-V-C) Reading Test: This consisted of $96 \mathrm{C}-\mathrm{V}-\mathrm{C}$ words; half of these were real words and half were nonsense words. Each word was presented individually to the child who was given one opportunity to read it. Two scores were taken for each subject; number of words read correctly and number of phonemes correct in each 'word' response. The second scoring method was used to measure reading at the first testing time, when the majority of the children were performing at floor level with the first measure.

(C-V-C) Spelling Test: Each child was asked to spell 32 of the words in the reading test. This subset consisted of 16 real words and 16 nonsense words. The real words were presented first; once alone, again in the context of a sentence, and a final time in isolation. Nonsense words were presented three times in isolation. To reduce memory load an alphabet of lower case letters was placed in front of the child during testing. As in the reading test, two scores were taken for spelling: at the initial testing we used number of letters spelled correctly, thereafter, the measure was the number of words spelled correctly .

\section{TESTS OF PHONOLOGICAL $\underline{\text { AWARENESS }}$}

Two different types of phonological tasks were chosen, a rhyme detection task and a phoneme segmentation task. Whereas early research into the relationship between reading 
and phonological awareness did not discriminate between different types of phonemic awareness tasks (Lewkowicz, 1980; Bradley and Bryant, 1985), more recent work suggests that the level of phonemic awareness demanded by the phonological tasks influences the strength of the relationship between reading and phoneme awareness (Backman, 1983). Stanovich, Cunningham and Cramer (1984 ) asked children to perform tasks involving the analysis of words for explicit sound content (nonrhyming tasks) and for the perception of overall similarity of sound content (rhyming tasks). They found that the nonrhyming, or analytic and productive phonological tasks formed a cluster of related skills and that the rhyming tasks did not correlate strongly with the nonrhyming tasks. Snowling and Perin (1983) found that children' ability to perform a segmentation task was not significantly different from their ability in spelling, the close connection between these skills indicating the necessity of explicit PA in spelling. Thus there seem to be two, developmentally different, measurable levels of PA. Children's first awareness of the sound properties of speech is implicit and perceptual. Spontaneous play with rhyming and nonsense words is thought to reflect an overall sensitivity to the sound content of words (Chukovsky, 1968; Slobin, 1978; Clark, 1977). At this point they are not yet able to consciously reflect on language (Shankweiler, Liberman and Savin, 1972; Andresen in Valtin, 1984). Valtin (1984) describes a three-stage model for the development of phonological awareness. Initially the child is not aware of the sound value of speech; s/he senses when, but not why, speech acts fail to be communicative. During the next stage, 'children become increasingly able to abstract the language from the action and the meaning context and to think about some of the properties of the form of language. Their knowledge of language units is still implicit, however, and related to psycholinguistic units of speech' (Valtin, 1984, p. 214). Once the child achieves conscious awareness, s/he demonstrates explicit phonological awareness and can reflect upon, produce and manipulate phonemic units within spoken words.

The knowledge that growth in phonological awareness follows a developmental continuum from implicit to explicit levels raises the question of how children utilize these different types of phonological awareness in their reading and spelling strategies. We used two 
Spelling and Learning to Read. 9

different phonological tasks in order to examine this question. The minimal requirement for success in rhyme detection is a global awareness of the sound property in words, while successful performance of phoneme segmentation tasks requires an explicit awareness of individual sounds within words. 
Implicit Awareness: Test of Auditory Organization (Bradley, 1980). The test of auditory perceptual organization is divided into three conditions: initial (comprised of words that begin with the same sound), final (with words that end with the same sound), and medial (containing words that share the same vowel sound). For each condition the child listens as a series of four words are spoken. S/he is asked to identify the 'odd one out' of the four words (the word that does not share a common sound component with the other three words). A warm-up procedure similar to that suggested by Bradley (1980) was used before testing each child.

Explicit Awareness: Phoneme segmentation test. A modification of the Elkonin procedure (Elkonin, 1973; Helfgott, 1976) was used to test ability in explicit phoneme segmentation. Each child was asked to perform three types of segmentation on 8 real C-V-C words and 8 nonsense $\mathrm{C}-\mathrm{V}-\mathrm{C}$ words given in spoken form. In the initial segmentation task subjects were asked to segment words into 2 parts; the initial consonant and the remaining vowelconsonant portion $(\mathrm{C}-\mathrm{VC})$. For the final segmentation task, the children were asked to segment the final sound from each word by producing the initial CV component followed by the final phoneme $(\mathrm{CV}-\mathrm{C})$. The complete segmentation task required each child to segment words into three distinct sound components $(\mathrm{C}-\mathrm{V}-\mathrm{C})$. The children practised each type of segmentation task before testing on that task commenced. Words within each type of task were presented in random order: real words were presented first, followed by nonsense words. Scores represent the total number of test words correctly segmented.

\section{LETTER-SOUND ASSOCIATIONS}

Knowledge of isolated letter-sound associations alone does not account for success in learning to read and spell. However, it does contribute to the development of reading (Ellis and Large, 1988) and use of letters helps children learn to segment words into constituent phonemes (Hohn and Ehri, 1983).

Test of Letter-Sound Knowledge: Each of the 26 lower case letters was presented individually on an $8.5 \mathrm{~cm}$ by $11 \mathrm{~cm}$ white card. The child was asked, 'What sound does this letter make?'. If the child responded with a letter name s/he was asked if s/he knew the sound it made; if the child gave the sound, the response was scored as correct. 


\section{WECHSLER PRESCHOOL AND PRIMARY SCALE OF INTELLIGENCE}

Five verbal and five performance tests were given to each child. Full scale scores on this test were used in the initial matching of groups for training and for purposes of partialling out the effect of IQ in the LISREL analyses.

\section{Lisrel Analysis Methodology}

In this study LISREL (Jöreskog and Sörbom, 1984; Saris and Stronkhorst, 1984) was used to formulate a descriptive model that identifies significant contributors to the early growth of literacy. With small samples LISREL is appropriate only for exploratory purposes (Crano and Mendoza, 1987). The limited number of subjects in this study restricts us to a preliminary structural equation model which needs further validation with a larger number of subjects. We fitted exploratory low constraint time-interval type models (Cataldo and Ellis, 1988, Ellis, 1989) where each ability could result from an effect of any ability measured at the previous time (Figure 1). This type of model allows us to compare the effects of two different abilities on a third ability. Table 1 gives the pathweight coefficients indicating the contribution of each ability to the development of later abilities. With standardized data, pathweights represent the amount of change in a variable (in standard deviation (sd) units) caused by one sd of change in another variable. In Table 1 the column headers represent the abilities measured at the prior time, the rows the effect variable measured at the later time; thus we can see that an increase of one sd in spelling ability at the beginning of the first school year was associated in an increase of $0.31 \mathrm{sds}$ in ability to read real words at the end of that year; in contrast, an increase of one sd of reading at the beginning of year one is only associated with an increase of $0.10 \mathrm{sds}$ in later spelling ability.

Figure 1 and Table 1 about here.

\section{Results and Discussion}

By broadening the phonological awareness-reading paradigm to include spelling, we are 
able to see a clearer picture of the early interaction among these abilities. Our model of reading and spelling development describes three measured phrases of development. Phase One spans the children's first year in school. Phase Two charts the development from spring of the first school year to autumn of the second year. Phase Three looks at development from the beginning of the second year in school to the beginning of the third year. The Phase One pathweights from spelling to reading real words $(0.31)$ and nonsense words $(0.23)$ identify spelling as an important contributor to the early formation of reading. This pattern of influence is repeated in the second phase (spelling to reading real words 0.64 and nonsense words 0.60 ). The pronounced influence of spelling on reading contrasts with the contribution of reading to spelling (Phase 1: 0.10 real words, 0. 06 nonsense; Phase 2: 0.14 real, 0.00 nonsense). Implicit PA initially predicts early attempts to read $(0.36,0.41)$ as well as to spell $(0.38,0.31)$ but looses its influence on both reading and spelling in the following two phases. In contrast to the diminishing predictive power of implicit PA, explicit PA consistently predicts spelling in all three phases, this influence increasing with phase. Explicit PA only emerges as a strong predictor of reading in Phase Three.

To summarize, the early flow of information between reading and spelling appears to be unidirectional: knowledge gleaned from spelling is contributing to reading. Similarly, both implicit and explicit PA affect spelling development with explicit PA increasing its influence as the contribution of implicit PA diminishes. Later in the developmental sequence, explicit PA begins to contribute directly to reading. The pattern of interactions among abilities in Phase one clarifies the different roles of implicit and explicit PA in the early formation of reading skill. Implicit information about the sound properties of words directly affects early reading attempts: explicit knowledge of phonemic content influences reading via spelling experience. Beginners may be be using implicit PA both to help them detect acoustic properties that define a word by its sound boundaries and to detect sounds with salient qualities, and their use of these rudimentary sound strategies allows them to form associations between sounds in spoken words and pronunciations and to call upon these associations to perform phonetic-cue reading (Ehri and Wilce, 1985). The use of implicit awareness of rhyming components in words may also help beginners to generalize from an 
unknown word to a word that contains a similar spelling (Bryant and Goswami, 1987), but this strategy is more likely to be employed at later stages of reading development when children have enough lexical entries from which to generalize. The first evidence of the direct influence of explicit PA on reading occurs in Phase Three, when explicit PA predicts ability to read nonwords. In earlier phases explicit PA does not influence reading directly but acts as the strongest predictor of spelling both real and nonsense words. In turn, spelling is the most consistent predictor of reading.

This early interactive sequence describes the pattern of growth from pre-alphabetic to alphabetic stage reading. While implicit knowledge of the sound properties of words helps children forge initial connections between the printed word and the perception of its pronunciation, spelling acts as a mediator for the use of explicit PA until the child begins alphabetic stage reading by directly applying explicit PA to reading. Our data suggests that as children practise spelling they develop proficiency in the use of the alphabetic principle and apply this knowledge to the task of reading. The emergence of explicit and productive PA as a significant predictor of reading marks the entry into the alphabetic stage of reading. Examination of the Phase Three pathweights suggests that children apply a strategy reliant on letter-sound knowledge and to a lesser degree, explicit PA to read real words, but lettersound knowledge and explicit PA jointly predict nonsense word reading. While learners appear to use a pre-alphabetic strategy with real words, they utilize a true alphabetic approach to nonsense words. This interpretation accords with children's introduction to reading during the first few years in school. They learn to rely on contextual clues and accompanying pictorial information in conjunction with distinctive graphic features in the printed word in order to arrive at a meaningful rendition of text. With increased reading experience, this early reading strategy is expanded to include reliance on partial phonetic cues accessed through constituent letters and on similarity of the component letters of the tobe-read-string to component letters of real words stored in the lexicon. In this way novice readers evolve a prealphabetic strategy that they associate with the quickest route to reading real words for meaning. But when children are confronted with nonsense or new words in the absence of meaningful context and analogous counterparts in the real word lexicon, they 
may switch to an alphabetic approach. Here we see evidence of the selective use of strategies for different purposes. Children are able to shift from one level of reading strategy to another, depending on the demands of the task. Beginners attempt to read unknown words via a strategy of combining context, visual and phonetic cues, and only when this fails, switch to deciphering. Initially, deciphering is used exclusively for reading unknown words when other strategies fail, but with practice children integrate this alphabetic approach into their repertoire set of strategies and eventually the beginner comes to appreciate the general usefulness of this deciphering strategy, perhaps temporarily reneguing other approaches to word recognition for the sake of practising this skill and gaining automaticity. Paradoxically, one way that a child could manifest movement into this new stage is by treating a word that was formerly mastered with a pre-alphabetic strategy as an unknown word and attempt to read it using a systematic sound strategy.

\section{A LONGITUDINAL STUDY OF PATTERN AND PREDICTION OF SPELLING ERRORS}

The idea that children's misspellings reflect a developing sense of phonetic properties in words was pioneered by Read $(1971,1975,1986)$ who found evidence that young inventive spellers used a system of grouping sounds together according to shared phonetic features. Thus they might represent a particular vowel sound in their spelling by substituting a letter whose name shared a salient phonetic feature with the sound. Read suggested that children use both production and perception of sound to group sounds together and that these categorizations may not coincide with the classification system used by adults. His exhaustive studies of invented spellings attuned further research to the analysis of misspellings in an attempt to uncover a developmental sequence for spelling that reflects a heightening awareness of the internal sound structure of words:

'We now value spellings for what they can tell us about psycholinguistic

processes. Standard spellings are of less interest, not because they represent successful instruction, but because they do not indicate how a child arrived at them... Some non-standard spellings represent a more advanced conception of the 
task or the language than others. Occasionally, we can even discern that the same spelling occurs for different reasons, one more advanced than another.' (Read, 1986, p. 47; see also Wilde, 1988).

The idea that spelling errors provide a gauge of how a child understands metalinguistic properties of language has led researchers to categorize developmental strategies in spelling. Henderson and Beers (1980) analyzed samples of children's creative writing and assigned each error to a category according to the completeness of phonetic information mapped by the misspelling. They charted movement from prephonetic to phonetic stages of spelling. As a result of their work and that of Gentry (1982), it is now generally agreed that children move through five distinct stages of spelling, viz, precommunicative, prephonetic, semiphonetic, phonetic, transitional and correct spelling. It is the first three of these developmental stages that are relevant to the question of how phonological awareness plays a role in children's early spelling. Precommunicative spellings are characterized by the strategy of randomly selecting letter strings to represent words. Although at this stage children can produce letters in writing, their spellings reflect a complete lack of letter-sound or letter-name knowledge. Semiphonetic spellings contain a partial mapping of phonetic content. Phonetic spellings contain a complete description of the sequence of sounds in pronunciations. Although precommunicative spellings are not regarded as reflecting the child's conscious attempts to map alphabet letters onto sounds in words, it is nevertheless plausible that some children who produce precommunicative spellings may possess the necessary segmentation ability but that their spelling efforts are blocked their ignorance of letter-sound associations, these children either abandoning their attempts or resorting to the arbitrarily selection of letters. If in beginning spelling the child segments sounds from a word and searches for a 'match' between phonetic information in the isolated sounds and information in letter-sound associates, a break down at the 'matching' stage could lead to precommunicative spellings.

Our results indicate that as spelling begins to take form, the beginner relies on a phonological strategy based on a perception of the overall sound content of words. In turn, these early endeavours in spelling contribute to an awareness of the general sound properties 
of words. In the next stage, as children begin to demonstrate proficiency in spelling with increasingly complete phonemic descriptions, the novice is more analytic in her approach to pronunciations. This progression from wholistic to analytic phonological strategy is analogous to the movement from semiphonetic to phonetic spelling proposed by Gentry (1982). In the above study we measured first-stage spelling by the number of phonemes correctly represented and second and third-stage spelling by number of words correctly spelled. Recognizing that children's misspellings provide valuable insight into the formation of spelling ability, we must now explore the relationships among different groupings of misspellings and different levels of PA. By including different types of error as well as correct spellings we can examine more closely the relative influence of each level of PA on the evolution of spelling strategy.

\section{Method}

\section{Subjects}

Only those subjects who produced at least five spelling errors were included in this analysis, since the amount of each type of error was measured in terms of percent of total errors for each subject and the inclusion of data for children who produce only a few errors would thus create a misleading picture of the early development of spelling strategies. This criterion of at least five spelling errors resulted in thirty-eight subjects at the first testing point, thirty-five subjects at the second, thirty at the third, and seventeen children at the final testing time.

\section{Procedure}

For the purpose of looking at the influence of PA on patterns spelling development, we classified misspellings in five categories that reflect increasing insight into the phonetic structure of the word. Our hierarchical classification of spelling errors is based on work by Henderson (1980), Morris (1983), and Gentry (1982). The most rudimentary spelling skill, 1st letter strategy, preserves only the information for the initial letter. Closer approximations have both boundary sounds intact. The highest level of informed error are partial-sequential and sequential errors where only the middle phoneme is in doubt: the representation of consonant sounds is 'safer' than vowel sounds in that consonant sounds are more reliably 
'matched' to letters on a one-to-one basis than are vowel sounds. Each spelling was handscored and assigned to a category of error based on the criteria described in Table 2. In Table 3 we show the mean number of such errors made at each testing time, the mean percentage of the child's total errors which this category of errors comprised, along with the mean performance on the explicit and implicit phonological awareness tests for each sound position.

\section{Results and Discussion}

The following general patterns emerge:

1) When children in this age band make a spelling error which bears any phonetic resemblance to the target, it is more often the case that only information for the initial consonant is preserved. Responses which are not totally correct, yet which approximate more than this to the correct phonetic analysis are more rare. The next most typical responses are those where both boundary sounds are correct (either with or without an incorrect intervening vowel).

2) By the time the children are at the beginning of year 3 the total numbers of errors has, of course, declined. Errors which fall into this hierarchical classification system become predominant (54\% at the beginning of years two and three vs $23 \%$ at the beginning of year 1) - the children are indeed moving from being precommunicative to semi-phonetic spellers. And this progression is also found within the semi-phonetic stage: the lowest phonemic content errors (1st letter intact) decline with age, and, in percentage terms at least, higher order errors (sequential and partial sequential) which preserve more of the phonetic content come to the fore.

3) The patterns of ability on explicit segmentation are highly positionally determined: children are most accurate at segmenting the initial sound from the rest. This contrasts dramatically with performance on the implicit task where children seem to be roughly as accurate at identifying the 'odd one out' whatever the position, initial, medial or final, of its errant sound, but with a slight tendency for them to have most difficulty with the alliterative task of the implicit initial condition (the same pattern was found by Bradley and Bryant, 
1985).

4) There is little measurable developmental improvement on the implicit segmentation task. In contrast there are large improvements in explicit segmentation skill during year one and the transition to year 2 .

In contrast to the pattern for implicit segmentation, that of explicit phoneme segmentation doubly mirrors that of spelling: it follows both its developmental surges and its positional sensitivity. This echoes the findings of Snowling and Perin (1983) that children's ability to perform an explicit segmentation task did not differ significantly from their ability in spelling, the close connection between these skills indicating the necessity of explicit PA in spelling.

Tables 2 and 3 about here

In order to explore the patterns of development within each level development, Spearman's rank correlations were computed between the subjects' percentage spelling errors of each type and their abilities on explicit segmentation (initial, final and complete) and implicit segmentation (initial, medial and final) within each testing time. The resultant correlations are shown in Table 4.

Table 4 about here.

Based on previous investigations and theories outlined in the text, we expected to see a strong association between both implicit and explicit PA and semiphonetic spelling. Semiphonetic spellings prove only a partial map of phonetic content: with implicit PA a child should be able to detect some of the sound content in a word and produce a partial spelling ('c' or 'ct' for $/ \mathrm{kat} /$ ). We also expected explicit PA to contribute to an analytic approach which should result in phonetic spellings that provide more complete mappings of words and that begin to show insight into the internal sound structure of words ('ca' or 'cet' for /kat). Furthermore we expected that phonemic segmentation skill for a particular position of the spoken word would be associated with spelling skill for that particular position in the word. The results showed:

1) As in our prior analyses, both implicit and explicit phonemic awareness is associated 
with spelling skill (total correct), with explicit awareness showing the strongest relationship.

2) The magnitudes of these correlations with total correct spellings tend to increase with age, the associations between phonological skill and spelling increase with skill development in this range.

3) The magnitudes of these correlations increase as we go from left to right in the table, from the most rudimentary of semiphonetic spellings where phonemic knowledge for only the first letter is preserved, through more thorough analysis (partial-sequential and sequential strategic errors), to completely correct spellings: these increasing associations validate the spelling error classification in terms of a hierarchy of increasing phonemic skill.

4) Some of the expected associations between phonemic analysis skill for a particular position in the spoken word and spelling ability on that position's letter are confirmed, but the most obvious, that for the initial letter sound, is lacking. There does seem to be a general significant association across the phases whereby explicit phoneme segmentation ability for the final sound is associated with correct spelling of that sound as indexed by boundary errors. Furthermore complete explicit segmentation is associated with sequential and partialsequential errors. It does seem to be the case that the level of explicit phonemic awareness predict the level of spelling mistake.

However, a pronounced pattern in each phase of development is the absence of a significant relationship between first-letter strategy and either level of PA. We had expected that an immature form of phonological awareness would be linked with use of the first-letter strategy. However, the consistent pattern of nonsignificant correlations between each level of PA and first-letter strategy does not suggest a connection between the two skills. This lack of apparent relatedness between either level of PA and first-letter spellings may be due to failure of the measurement tools to detect the nascent level of PA used by the children. It is possible that neither the the explicit (initial) test nor the implicit (initial) test tapped the incipient level of phonological awareness that helps children produce first-letter spellings. Beginners may use a simpler method of extracting relevant phonetic information from the beginning of a word than a complete segmentation of the initial phoneme from the rest ('cat' $>/ \mathrm{k} /$-/at/) required in the explicit segmentation task, and perhaps, in retrospect, we should 
have tested for ability to segment just the initial sound from the word ('cat' ->/k/) in order to tap this most rudimentary of explicit segmentation abilities. In the same way the initial condition of the test of auditory categorization may be too demanding in terms of memory load and individual differences may be reflecting working memory capacity as much as ability to use alliteration. A version of this task that required comparison of the beginning sounds in two instead of three and four words may serve the purpose of measuring implicit PA as it first develops.

5) Although it is generally true that explicit segmentation ability is the stronger associate of spelling than implicit segmentation skill, it is nonetheless true that both skills are increasing in their relationship with spelling as it develops. It is tempting to conclude that the influence of explicit PA on the ability of children to produce correct spellings reflects an explicit phoneme segmentation strategy in spelling whilst the increasing association between implicit segmentation skill and spelling reflects them using ability to detect rhyme to help them arrive at spellings by analogy. By the beginning of the third year in school, when our subjects were last tested, the children's on-going reading and spelling experience would have helped them build up a store of lexical entries. It is plausible that the ability to detect rhyme, as measured on the final and medial conditions of the test of auditory categorization, could be used at this point to make the connection between a word to be spelled and a rhyming word in the child's collection of lexical entries. This method of using rhyme to spell by analogy is similar to reading by analogy as described by Bryant and Goswami (1987).

Enough of a sensible pattern has emerged from this analysis of the way explicit and implicit PA are associated with the development of early spelling strategies to reassure us that phonemic awareness is an essential prerequisite of spelling. But much remains to be done on the details of the associations: (1) Our categorization system for spelling errors serves, but it needs refinement (e.g. we used misspellings that contained letters present in the correct word spellings so that the misspelling 'ct' for /kat/ would be categorized as a phonetically relevant error, but the misspelling 'gt' would be classified as a precommunicative error that did not necessarily reflect a mapping of the sounds in /kat/. However, 'gt' may be a misspelling 
worth noting, as the letter ' $\mathrm{g}$ ' represents a sound that is identical with the sound represented by ' $c$ ' in two different articulatory features, place and manner and different in only one, voicing). (2) We must in further analyses cumulate across positions (eg we have separately analysed for initial letter skill, ignoring the fact that that ability is also demonstrated in all other categories of error, and even the correct response). (3) In future testing we must use simpler initial segmentation tasks which are more sensitive to ability on that sound alone. (4) As in our other work, we must analyse for longitudinal development, looking for predictions from prior abilities to later ones.

\section{CONCLUSIONS}

Models of reading and spelling must describe development, the movement from one stage to the next. Our results describe the ways in which spelling acts as a mediator for the influence of explicit phonological awareness on reading. Children's very first efforts at reading are characterized by a visual or logographic strategy where letters are analyzed for salient graphic cues to rapid word recognition; this is the PreAlphabetic Stage. When a small number of pronunciations can be accessed in this manner, the child may embark upon a more advanced strategy of using associations between partial phonetic cues in the spoken word with letters in the printed version and subsequently utilize these associations to recognize the words. Children appear to use implicit and perceptual PA to help them make these rudimentary sound analyses of pronunciation. In addition, spelling practice may contribute to the store of associations between the spoken words and letter-sound constituents in printed words. At first, spelling may encourage children to focus on the first letter of printed words and to begin to analyse this first letter, in the reading task, for phonetic cues to pronunciations. Thus, the practice of turning attention to the first lettersound unit in spelling may influence children to discriminate between stored pronunciations on the basis of the first letter of the printed word. This method of early word recognition is described by Marsh et al. (1981) as 'discrimination net substitution'. As visual and phonetic cue strategies make increasing demands on the child's memory, the efficiency of this strategy decreases. Conversely, as the source of knowledge about letter-sound associates, and the relationships between letters in printed words and sounds in spoken words swells, the child 
is discovering that $\mathrm{s} / \mathrm{he}$ can rely on the use of this knowledge for successful word recognition. Our studies support the idea that the transition from pre-alphabetic stage reading to alphabetic stage reading is facilitated by spelling. By employing explicit and productive PA in spelling practice, the child gains familiarity with the alphabetic nature of writing and builds a reliable fund of information about letter-sound correspondences and explicit phonemic content in words. Spelling affords the opportunity to forge a meaningful link between phonological awareness and letter-sound knowledge. This connection is a prerequisite to the development of phonological strategies in reading. Furthermore, the data suggest that progress from the pre-alphabetic stage of literacy to the alphabetic stage involves an overlapping of strategies and in this sense there is no one 'reading' but rather a cascade of very different strategic blends of information processing skills being used at different points in fast changing stream of the development of reading (Ellis and Large, 1988, Ellis, 1989).

\section{IMPLICATIONS FOR TEACHING}

These are but a few more words contributing to The Great Debate (Chall, 1967) concerning the 'best' ways of teaching reading, at the core of which vie methods based on look-and-say, phonics, spelling and meaning. Over the decades each has ascended and waned in almost predictably recurrent cycles.

"The alphabet method, in spite of occasional protest, was almost universally used from the Greek and Roman times until some thirty years ago, and of course has not been discarded even yet. In this method the child learned first the names of the large and small letters and their order in the alphabet. This was task enough, uninteresting as it was to many, to keep them employed for some months, or even in some cases for a year or more. Then the combinations like $a b$, $e b, i b$ were spelled out and pronounced, and then three-letter combinations like glo, flo, pag, etc., in all of which the early pages of the old spellers abounded.... Spelling the word preceded its pronunciation, until it was well known. It was assumed that there was a necessary connection between naming the letters of a word and pronouncing that word." (Huey, 1908, pp 254-255).

"Just how naming the letters was supposed to assist in pronouncing the word it is difficult to see. The value of practice in learning to spell doubtless had much to do with blinding centuries of teachers to its uselessness for the reading of 
words and sentences. However, in dealing thus constantly with the letters and their combinations, the pupil necessarily acquired a familiarity with the sounds represented by each letter, whether purposely these taught or not. And thus this method always combines something of phonics as well. ... The phonic method, used by the Jansenists in the Port Royal Schools, long neglected but advocated again by Thornton in 1790 ... It is a spelling method, but the word is spelled by its elementary sounds and not by the letter-names. The word is slowly pronounced until its constituent sounds come into consciousness, and these sounds are associated with the letters representing them. Drill in this sound analysis trains the articulation, trains the ear and the ability to sound the letters of any new word, and gives the power to pronounce it by blending the sounds suggested." (Huey, 1908, p 266, our emphasis).

In 1908 Huey decries the spelling methods which involve the names of letters, but he does acknowledge the advantages of training in phonics. Yet at the same time he equivocates and is concerned about teaching which concentrates on the 'mechanics' of reading:

"It seems a great waste to devote, as at present, the main part of a number of school years to the mere mechanics of reading and spelling. The unreasoned and unreasonable devotion to our irrational English spelling in itself robs the child of probably two whole years of school life... the results too often show only mechanical, stumbling, expressionless readers, and poor thought-getters from what is read. The mechanical reading is thought to come from learning reading as mere word-pronouncing; the stumbling and hesitation, from the over-attention to form as against content, especially from the early and too constant analysis of the reading process in phonics." (Huey, 1908, p 301-302).

In response to such criticisms, from the 1930s on, modal reading tuition was based on principles which "include as major goals, right from the start, not only word recognition, but also comprehension and interpretation, appreciation, and application of what is read to the study of personal and social problems. .. Drill or practice 'in isolation' (i.e., apart from the reading of sentences or stories) should be avoided; instead, phonics should be 'integrated' with the 'meaningful' connected reading. In addition, the child should not isolate sounds and blend them to form words. Instead, he should identify unknown words through a process of visual analysis and substitution." (Chall, 1967, pp 13-15).

The pendulum followed its natural return in America in the mid-1950s with Flesch's popular Why Johnny Can't Read which challenged the then prevailing emphasis on sightmethod teaching and which advocated a return to a phonic approach as the best, nay only, method to use in beginning instruction, and in Britain with the evaluation studies of Daniels 
and Diack (1956) which demonstrated a superiority of their 'phonic-word method' over the current mixed methods.

And again, two decades later, the position swings back away from phonics and spelling to Smith's 'psycholinguistics guessing game':

"Reading is not 'decoding to sound'." (Smith, 1978, p.83). "Mediated word identification ...strategies... include the use of phonics (spelling-sound correspondences). Attempting to decode isolated words to sound is unlikely to succeed because of the number, complexity, and unreliability of phonic generalisations. Phonic rules will help to eliminate alternative possibilities only if uncertainty can be reduced by other means, for example, if the unfamiliar words occur in meaningful contexts. Spelling-sound correspondences are not easily or usefully learned before children acquire some familiarity with reading." (Smith, 1978, p. 150)

"Of course, spelling is a problem, both in school and out, but it is a problem of writing, not of reading....Knowing how to spell does not make a good reader because reading is not accomplished by the decoding of spelling....I am not saying that knowledge of spelling is not important, only that it does not have a role in reading, and that undue concern with the way in which words are spelled can only interfere with a child's learning to read" (Smith, 1978, p. 143).

Our present results lead us firmly to believe that Smith is wrong in these claims, and, taken with the work of Bradley and Bryant, Downing, Ehri, Elkonin, Frith, and Miles and Miles, they constitute an impetus back to methods of reading teaching which involve spelling and phonics. This direction is furthermore reaffirmed by the accumulation of evidence from evaluative studies of differing teaching methods that phonic and spelling-pattern training is particularly effective. Thus Chall's (1967) exhaustive meta-analysis of the studies performed between 1910 and 1965 concludes:

(1) a code (phonics) emphasis tends to produce better overall reading achievement by the beginning of the fourth grade than a meaning emphasis, with greater accuracy in word recognition and oral reading from the very beginning, and better vocabulary and comprehension scores by mid-second grade. With a code emphasis the child seems to initially read more slowly because of the greater emphasis on accuracy, however, by the third or fourth grade when he is more fluent his rate is equal to, or may ultimately exceed that produced by a meaning emphasis. 
(2) Systematic-phonics programmes that rely on direct teaching of letter-sound relationships are as successful as, or perhaps more successful than, programs that rely on 'discovery' - the so-called linguistic approaches that do not teach letter-sound correspondences directly.

We find, similarly, in Bradley and Bryant's training study (1983) that when children who were backwards in reading at 4 and 5 years old were trained on sound categorisation they showed markedly greater improvements in reading over the next two years than those who were given semantic categorisation training. However, those children who were given sound categorisation and, with the help of plastic letters, were additionally taught how each common sound was represented by a letter of the alphabet, showed even greater improvement. Furthermore, less than 10 hours of such training spaced over two years led to these superiorities in reading being sustained through until the children were 13 years old (Bradley, 1989). We can conclude from these results that phonic training is particularly effective for individuals who are retarded in reading, and, furthermore, training in sound categorisation is even more effective when it is linked to spelling and involves an explicit connection with the alphabet.

Our results demonstrate the growth of cognitive skills which explain these findings. Within a developmental context, explicit phoneme awareness initially appears to grow out of an implicit appreciation of the overall sound properties of words. Then explicit phonemic awareness is itself an important factor in the first stages of spelling development, emerging only later as a significant contributor to reading. The early influence of explicit phoneme awareness on spelling, in conjunction with the major contribution of spelling to beginning reading, indicates that experience in spelling promotes the use of a phonological strategy in reading. Thus training phonics and spelling to individuals who have not yet acquired these particular phonological skills nor related them to spelling patterns will eventually help them to become proficient readers. In saying this we are not advocating a return to Huey's 'mere mechanics of reading and spelling. The unreasoned and unreasonable devotion to our irrational English spelling', we are certainly not suggesting spelling by letter names, rather we promote the notion of reading programmes which include the wide range of goals from 
word attack skills, through comprehension to interpretation and which are tailored to the needs of the particular child and particular stage (Ellis and Large, 1988; Frith, 1985) of reading development. However, we do believe that it is advisable for beginning readers and those who are backwards or specifically retarded to be assisted in developing facility in dissecting a word's sound structure so as to foster symbol-sound and sound-symbol association. At times this must involve the direct teaching of these associations.

The other conclusion concerns the early identification of children at risk. The work of Bradley (1989) demonstrates that the younger the child the more effective is remedial intervention. We do not need to wait until children are seven or eight years of age or older to identify that they are falling substantially behind in their reading development. Our present description of the growth of reading skill identifies its precursors as phonological skills and early spelling. We can therefore use young children's problems in these areas as indices predictive of risk of later reading delay. 


\section{REFERENCES}

Alegria, J., Pignot, E. and Morais, J. (1982) Phonetic analysis of speech and memory codes in beginning readers. Memory and Cognition, 10, 451-456.

Backman, J. (1983) The role of psycholinguistic skills in reading acquisition: a look at early readers. Reading Research Quarterly, 18, 466-479.

Baddeley, A.D. (1979) Working memory and reading. In P. A. Kolers, M. E. Wrolstad and H. Bouma (Eds.) Processing of Visible Language, Vol. 1. New York: Plenum Press.

Bradley, L. (1980) Assessing Reading Difficulties: a diagnostic and remedial approach. London: Macmillan Education.

Bradley ,L. and Bryant, P. E. (1983) Categorizing sounds and learning to read - a causal connection. Nature, 301, 419-421.

Bradley, L. and Bryant, P. (1985) Rhyme and Reason in Reading and Spelling. (International Academy for Research in Learning Disabilities, No. 1) Ann Arbor: The University of Michigan Press.

Bradley, L. (1989) Specific learning disability: prediction - intervention - progress. Paper presented to the Rodin Remediation Academy International Conference on Dyslexia, University College of North Wales, September, 1989

Bryant, P.E. and Bradley, L. (1980) Why children sometimes write words which they do not read. In U. Frith (Ed.) Cognitive Processes in Spelling. London: Academic Press.

Bryant, P.E. and Bradley, L. (1985) Children's Reading Problems. Oxford: Blackwell

Bryant, P.E. and Goswami, U. (1987) Phonological awareness and learning to read. In J.R. Beech and A.M. Colley (Eds.) Cognitive Approaches to Reading. Chichester: Wiley.

Cataldo, S. and Ellis, N. (1988) Interactions in the development of spelling, reading and phonological skills. Journal of Research in Reading, 11(2), 86-109.

Cataldo, S. and Ellis, N.C. (In Press, 1990) "Learning to Spell, Learning to Read". To appear in P.D. Pumphrey and C.D. Elliott (Eds.) Children's Difficulties in Reading, Writing and Spelling: Challenges and Responses. Baisingstoke: Falmer Press.

Chall, J. (1967) Learning to Read: The Great Debate. New York: McGraw-Hill.

Chomsky, C. (1977) Approaching reading through invented spelling. In L.B. Resnick and 
P.A. Weaver (Eds.) The Theory and Practice of Early Reading. Vol. 2. Hillsdale, N.J.: Erlbaum.

Chukovsky, K. (1968) From Two to Five. Berkeley: University of California Press.

Clark, E. V. (1978) Awareness of language: some evidence from what children say and do. In A. Sinclair, R.J. Jarvella and W.J.M. Levelt (Eds.) The Child's Conception of Language. New York: Springer-Verlag.

Crano, W.D. and Mendoza, J.L. (1987) Maternal factors that influence children's positive behaviour: demonstration of a structural equation analysis of selected data from the Berkeley Growth Study. Child Development, 58, 38-48.

Daniels, J.C. and Dyack, H. (1956) Progress in Reading. University of Nottingham: Institute of Education.

Downing, J. (1973) Comparative Reading: Cross National Studies of Behaviour and Processes in Reading and Writing. New York: Macmillan

Ehri, L.C. (1979) Linguistic insight: threshold of reading acquisition. In T.G. Waller and G.E. MacKinnon (Eds.) Reading Research: Advances in Theory and Practice. Vol. 1. New York: Academic Press.

Ehri, L.C. and Wilce, L.S. (1985) Movement into reading: is the first stage of printed word learning visual or phonetic? Reading Research Quarterly, 20, 163-179.

Ehri, L.C. and Wilce, L.S. (1987a) Does learning to spell help beginners learn to read words? Reading Research Quarterly, 22, 47-65.

Ehri, L.C. and Wilce, L.S. (1987b) Cipher versus cue reading: an experiment in decoding acquisition. Journal of Educational Psychology, 79, 3-13.

Elkonin, D.B. (1973) U.S.S.R. In J. Downing (Ed.) Comparative Reading. New York: Macmillan.

Ellis, N.C. (In Press, 1989) "Reading, Phonological Processing and STM: Interactive Tributaries of Development" To appear in Journal of Research in Reading

Ellis, N. and Large, B. (1987) The development of reading: as you seek so shall you find. British Journal of Psychology, 78, 1-28.

Ellis, N. and Large, B. (1988) The early stages of reading: a longitudinal study. Applied 
Cognitive Psychology, 2, 47-76.

Flesch, R. (1955) Why Johnny Can't Read and What You Can Do about It. New York: Harper and Brothers.

Frith, U. (1981) 'Experimental approaches to developmental dyslexia: an introduction.' Psychological Research,43, 97-110.

Frith, U. (1985) Beneath the surface of developmental dyslexia. In K. Patterson, M. Coltheart and J. Marshall (Eds.) Surface Dyslexia. London: Erlbaum.

Gentry, J.R. (1982) Analysis of developmental spelling in GNYS AT WORK. The Reading Teacher, 36, 192-200.

Goswami, U. (1986) Children's use of analogy in learning to read: a developmental study. Journal of Experimental Child Psychology, 42, 73-83.

Gough, P.B. and Hillinger, M.L. (1980) Learning to read: an unnatural act. Bulletin of the Orton Society, 30, 171-176.

Harris and Coltheart, M. (1986) Language Processing in Children and Adults. London: Routledge and Kegan Paul.

Helfgott, J.A. (1976) Phonemic segmentation and blending skills of kindergarten children: implications for beginning reading acquisition. Contemporary Educational Psychology, 1, 157- 169 .

Henderson, E.H. (1980) Developmental concepts of words. In E.H. Henderson and J.W. Beers (Eds.) Developmental and Cognitive Aspects of Learning to Spell: A Reflection of Word Knowledge. Newark, Del.: International Reading Association.

Henderson, E.H. and Beers J.W. (1980) (Eds.) Developmental and Cognitive Aspects of Learning to Spell: A Reflection of Word Knowledge. Newark, Del.: International Reading Association.

Hohn, W.E. and Ehri, L.C. (1983) Do alphabet letters help prereaders acquire phonemic segmentation skill? Journal of Educational Psychology, 75, 752-762.

Huey, E.B. (1908) The Psychology and Pedagogy of Reading. Cambridge, Mass.: M.I.T. Press.

Jöreskog, K.G. and Sörbom, D. (1984) Lisrel VI User's Guide. Uppsala: Department of 
Statistics.

Juel, C., Griffith, P.L. and Gough, P.B. (1986) The acquisition of literacy: a longitudinal study of children in first and second grade. Journal of Educational Psychology, 78, 243-255.

Lewkowicz, N.K. (1980) Phonemic awareness training: what it is and how to teach it. Journal of Educational Psychology, 72, 686-700.

Liberman, I.Y. and Shankweiler, D. (1979) Speech, the alphabet, and teaching to read. In Resnick, L.B. and Weaver, P.A. (Eds.) Theory and Practice of Early Reading. Hillsdale, N.J.: Erlbaum.

Lomax, R.G. and McGee, L.M. (1987) Young children's concepts about print and reading: toward a model of word reading acquisition. Reading Research Quarterly, 22, 237-256.

Marsh, G., Friedman, M.P., Welch, V. and Desberg, P. (1980) The development of strategies in spelling. In U. Frith (Ed.) Cognitive Processes in Spelling. London: Academic Press.

Marsh, G., Friedman, M.P., Welch, V. and Desberg, P. (1981) A cognitive-developmental theory of reading acquisition. In T.G. Waller and G.E. MacKinnon (Eds.) Reading Research: Advances in Theory and Practice. Vol. 3. New York: Academic Press.

Miles, T.R. and Miles, E. (1975) More Help for Dyslexic Children. London: Methuen Educational.

Mommers, M.J.C. (1987) An investigation into the relationship between word recognition, reading comprehension and spelling skills in the first two years of primary school. Journal of Reading Research, 10, 122-143.

Morias, J., Cary, I.L., Alegria, J. and Bertelson, P. (1979) Does awareness of speech as a sequence of phones arise spontaneously? Cognition, 7, 323-331.

Morris, D. (1983) Concept of word and phoneme awareness in the beginning reader. Research in the Teaching of English, 17 (4), 359-373.

Morris, D. and Perney, J. (1984) Developmental spelling as a predictor of first-grade reading achievement. The Elementary School Journal, 84 (4), 441-457.

Read, C. (1971) Preschool children's knowledge of English phonology. Harvard Educational Review, 41, 1-34. 
Read, C. (1975) Children's Categorizations of Speech Sounds in English. Urbana, Ill.: National Council of Teachers of English.

Read, C. (1986) Children's Creative Spelling. London: Routledge and Kegan Paul.

Saville, P. (1971) A British Supplement to the Manual of The Wechsler Preschool and Primary Scale of Intelligence. Windsor: NFER-Nelson.

Saris, W.E. and Stronkhorst, H.L. (1984) Causal Modelling in Nonexperimental Research. Amsterdam: Sociometric Research Foundation.

Seymour, P.H.K. and Elder, L. (1985) Beginning reading without phonology. Cognitive Neuropsychology, 1, 43-82.

Shanahan, T. and Lomax, R. G. (1986) An analysis and comparison of theoretical models of the reading-writing relationship. Journal of Educational Psychology, 78, 116-123.

Shankweiler, D., Liberman, I.Y. and Savin, (1972) General discussion of papers. In J.F. Kavanagh and I. Mattingly (Eds.) Language by Ear and by Eye. Cambridge, Mass: MIT Press.

Silberberg, N.E., Iver, A., Iverson, M.S. \& Goins, J.T. (1973) Which remedial reading method works best? Journal of Learning Disabilities, 6, 18-27.

Slobin, D.J. (1978) A case study of early language awareness. In A. Sinclair, J. Jarvella and W.J.M. Levelt (Eds.) The Child's Conception of Language. New York: SpringerVerlag.

Smith, F. (1978) Understanding Reading: A Psycholinguistic Analysis of Reading and Learning to Read. 2nd Edition. New York: Holt, Rinehart and Winston.

Snowling, M. and Perin, D. (1983) The development of phoneme segmentation skills in young children. In J. Sloboda (Ed.) The Aquisition of Symbolic Skills. London: Plenum Press.

Stanovich, K.E., Cunningham, A.E. and Cramer, B.B. (1984) Assessing phonological awareness in kindergarten children: issues of task comparability. Journal of Experimental Child Psychology, 38, 175-190.

Tornéus,M. (1984) Phonological awareness and reading: a chicken and egg problem? Journal of Educational Psychology, 76 (6), 1346-1358. 
Valtin, R. (1984) The development of metalinguistic abilities in children learning to read and write. In J. Downing and R. Valtin (Eds.) Language Awareness and Learning to Read. New York: Springer-Verlag.

Wechsler, D. (1967) Manual for the Wechsler Preshool and Primary Scale of Intelligence. New York: The Psychological Corporation New York.

Wilde, S. (1988) Learning to spell and punctuate: A study of eight- and nine-year old children. Language and Education, 2 (1), 35-39. 


\section{Acknowledgements}

We thank the headteachers, teachers and pupils of St. Gerards Convent School, Bangor, Our Ladies Roman Catholic School, Bangor, and Llandegfan Primary School, Anglesey for their constant help, encouragement and patience throughout the three years of this project. Parts of this work are also reported in our chapter in P.D. Pumphrey and C.D. Elliott (Eds.) Primary School Pupils' Reading and Spelling Difficulties: Current Research and Practice. Baisingstoke: Falmer Press, 1990. 


\section{Figure legend}

Figure 1. An illustration of the LISREL model used. All possible paths were allowed between adjacent time periods, thus allowing each variable to potentially contribute to the development of every other variable at the next time-point. However, in order not to clutter the diagram, we have not shown all the paths between stages - we have only illustrated this for Spelling in the Figure. See text for further details. 
Table 1

LISREL path coefficients indicating contributions of early ability to development of later abilities

(Path coefficients in bold are significant at $p<.05$ )

(READ: Reading; SPELL: Spelling; EXPL.PA: Explicit Phonological Awareness; IMPL.PA:

Implicit Phonological Awareness; LS: Letter Sound. See text for details.)

READING-SPELLING MODEL

PHASE ONE: BEGINNING FIRST SCHOOL YEAR TO END OF FIRST SCHOOL YEAR

\begin{tabular}{|c|c|c|c|c|c|}
\hline GAMMA & READ & SPELL & EXPL.PA & IMPL.PA & LS \\
\hline $\begin{array}{l}\text { READ } \\
\text { (real) }\end{array}$ & 0.37 & 0.31 & 0.08 & 0.36 & 0.06 \\
\hline $\begin{array}{l}\text { READ } \\
\text { (non) }\end{array}$ & 0.18 & 0.23 & 0.17 & 0.41 & 0.08 \\
\hline $\begin{array}{l}\text { SPELL } \\
\text { (real) }\end{array}$ & 0.10 & 0.35 & 0.32 & 0.38 & 0.07 \\
\hline $\begin{array}{l}\text { SPELL } \\
\text { (non) }\end{array}$ & 0.06 & 0.24 & 0.31 & 0.31 & 0.21 \\
\hline $\begin{array}{l}\text { EXPL. } \\
\text { PA }\end{array}$ & -0.04 & 0.13 & 0.42 & 0.36 & 0.11 \\
\hline $\begin{array}{l}\text { IMPL. } \\
\text { PA }\end{array}$ & 0.15 & 0.53 & 0.06 & 0.49 & -0.20 \\
\hline
\end{tabular}

PHASE TWO: END OF FIRST YEAR TO AUTUMN OF SECOND YEAR

\begin{tabular}{|c|c|c|c|c|c|c|}
\hline BETA & $\begin{array}{l}\text { READ } \\
\text { REAL }\end{array}$ & $\begin{array}{l}\text { READ } \\
\text { NON }\end{array}$ & $\begin{array}{l}\text { SPELL } \\
\text { REAL }\end{array}$ & $\begin{array}{l}\text { SPELL } \\
\text { NON }\end{array}$ & $\begin{array}{ll}\text { EXPL. I } \\
\text { PA }\end{array}$ & \\
\hline $\begin{array}{l}\text { READ } \\
\text { (real) }\end{array}$ & 0.66 & -0.34 & 0.64 & -0.10 & 0.21 & -0.25 \\
\hline $\begin{array}{l}\text { READ } \\
\text { (non) }\end{array}$ & 0.31 & 0.07 & 0.60 & -0.09 & 0.18 & -0.09 \\
\hline $\begin{array}{l}\text { SPELL } \\
\text { (real) }\end{array}$ & 0.14 & -0.33 & 0.76 & -0.02 & 0.34 & 0.07 \\
\hline $\begin{array}{l}\text { SPELL } \\
\text { (non) }\end{array}$ & 0.00 & -0.04 & 0.77 & -0.22 & 0.45 & 0.05 \\
\hline $\begin{array}{l}\text { EXPL. } \\
\text { PA }\end{array}$ & 0.34 & -0.10 & -0.02 & 0.20 & 0.50 & 0.03 \\
\hline $\begin{array}{l}\text { IMPL. } \\
\text { PA }\end{array}$ & 0.27 & 0.37 & -0.22 & -0.19 & 0.35 & 0.12 \\
\hline LS & 0.36 & 0.24 & -0.20 & -0.14 & 0.26 & -0.08 \\
\hline
\end{tabular}

PHASE THREE: BEGINNING OF SECOND YEAR TO BEGINNING OF THIRD YEAR

\begin{tabular}{|c|c|c|c|c|c|c|c|}
\hline BETA & $\begin{array}{l}\text { READ } \\
\text { REAL }\end{array}$ & $\begin{array}{l}\text { READ } \\
\text { NON }\end{array}$ & $\begin{array}{l}\text { SPELL } \\
\text { REAL }\end{array}$ & $\begin{array}{l}\text { SPELL } \\
\text { NON }\end{array}$ & $\begin{array}{lc}\text { EXPL. } & \text { IMPL } \\
\text { PA } & \text { PA }\end{array}$ & LS & \\
\hline$======$ & $=======$ & $======$ & $========$ & $=========$ & $===========$ & $======$ & 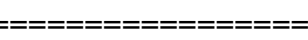 \\
\hline $\begin{array}{l}\text { READ } \\
\text { (real) }\end{array}$ & 0.20 & 0.24 & 0.00 & -0.12 & 0.30 & 0.08 & 0.38 \\
\hline $\begin{array}{l}\text { READ } \\
\text { (non) }\end{array}$ & 0.03 & 0.22 & -0.00 & -0.05 & 0.53 & 0.01 & 0.30 \\
\hline $\begin{array}{l}\text { SPELL } \\
\text { (real) }\end{array}$ & 0.03 & 0.01 & 0.04 & -0.10 & 0.63 & 0.09 & 0.09 \\
\hline SPELL & 0.21 & 0.43 & -0.32 & 0.13 & 0.49 & 0.27 & 0.17 \\
\hline
\end{tabular}


Spelling and Learning to Read. 36

(non) 


\section{Table 2}

\section{CATEGORIES OF SPELLING ERROR}

Description of each error type with examples from data.

(Example spellings followed by pronunciation of target word in //.)

\begin{tabular}{|c|c|c|c|}
\hline $\begin{array}{l}\text { FIRST LETTER } \\
\text { STRATEGY }\end{array}$ & $\begin{array}{l}\text { BOUNDARY } \\
\text { SOUNDS } \\
\text { STRATEGY }\end{array}$ & $\begin{array}{l}\text { PARTIAL- } \\
\text { SEQUENTIAL } \\
\text { STRATEGY }\end{array}$ & $\begin{array}{l}\text { SEQUENTIAL } \\
\text { STRATEGY }\end{array}$ \\
\hline INITIAL CONS & $\begin{array}{l}\text { INITIAL-FINAL } \\
\text { CONSONANTS }\end{array}$ & CV SEGMENT & $\begin{array}{l}\text { CVC UNIT } \\
\text { INCOR V }\end{array}$ \\
\hline $\mathrm{C} / \mathrm{KOD} /$ & $\mathrm{CD} / \mathrm{KOD} /$ & $\mathrm{CO} / \mathrm{KOD} /$ & $\mathrm{REF} / \mathrm{RIF} /$ \\
\hline $\begin{array}{l}\text { INITIAL CONS } \\
\text { PLUS INCOR } \\
\text { LETTER(S) }\end{array}$ & $\begin{array}{l}\text { INITIAL-FINAL } \\
\text { CONSONANTS + } \\
\text { EXTRA LETTERS }\end{array}$ & $\begin{array}{l}\text { CV SEGMENT } \\
\text { + INCOR } \\
\text { FINAL CONS }\end{array}$ & $\begin{array}{l}\text { CVVC UNIT } \\
\text { ONE OR TWO } \\
\text { INCOR V }\end{array}$ \\
\hline \multirow[t]{5}{*}{$\begin{array}{l}\text { CGTZNY /KOD/ } \\
\text { CAN /KOD/ }\end{array}$} & $\begin{array}{l}\text { GBC /GUB/ } \\
\text { WDNGIST /WID/ } \\
\text { BSI /BIS/ }\end{array}$ & $\mathrm{COT} / \mathrm{KOD} /$ & HIED /HID/ \\
\hline & $\begin{array}{l}\text { INITIAL-FINAL } \\
\text { CONS EMBEDDED } \\
\text { IN STRING }\end{array}$ & $\begin{array}{l}\text { CV SEGMENT } \\
\text { + EXT LET }\end{array}$ & $\begin{array}{l}\text { CVC + } \\
\text { EXTRA LET } \\
\text { (V INCOR) }\end{array}$ \\
\hline & $\begin{array}{l}\text { MWDS /WID/ } \\
\text { BERBO /RUB/ }\end{array}$ & COWZO /KOD/ & $\begin{array}{l}\text { DELL /DAL/ } \\
\text { BASUS /BIS/ }\end{array}$ \\
\hline & $\begin{array}{l}\text { INITIAL + FINAL } \\
\text { CONS AT BOUNDS } \\
\text { OF STRING }\end{array}$ & $\begin{array}{l}\text { CV SEGMENT } \\
\text { EMBEDDED IN } \\
\text { LETTER STRING }\end{array}$ & \\
\hline & $\begin{array}{l}\text { FOATL /FUL/ } \\
\text { SRRN /SAN/ } \\
\text { WAESD /WID }\end{array}$ & MNOP /NOL/ & \\
\hline
\end{tabular}

CORREC MAPPINI

CVC UNIT

+ EXTRA

NOLME /NC FISS /FIS/

CORRECT SPELLING

$\mathrm{COD} / \mathrm{KOD} /$

Notes on scoring: When scoring children's early attempts to spell it was necessary to evaluate letter-forms that were either crudely formed or printed in the opposite direction. In the former case, we relied on notes taken for each child during testing. Letters printed in the reverse direction were scored correctly. Children frequently printed the letters s, h, r, a, c, and $\mathrm{p}$ in the opposite direction. In the case of the letters $\mathrm{b}$ and $\mathrm{d}$, it was decided to score 'reversals' as correct responses due to the frequency with which children verbally segmented the proper sound $(/ \mathrm{b} /$ or $/ \mathrm{d})$, pointed to the correct letter $(\mathrm{b}$ or $\mathrm{d})$, and proceeded to produce 
Spelling and Learning to Read. 38

the letter in the opposite direction. 
Table 3: Descriptive Data

Mean raw scores for each category of SPELLING errors at the four testing times*

CATEGORIES OF ERROR**

$\begin{array}{cccc}\text { 1ST LETTER } & \text { BOUNDARY } & \text { PARTIAL- } & \text { SEQUENTIAL } \\ \text { INTACT } & \text { INTACT } & \text { SEQUENTIAL } & (\text { CVC INTACT) } \\ / \mathrm{CAT} /=^{\prime} \mathrm{C}^{\prime} & / \mathrm{CAT} /=^{\prime} \mathrm{CT} & / \mathrm{CAT} /=^{\prime} \mathrm{CA}^{\prime} & / \mathrm{CAT} /=^{\prime} \mathrm{CET}{ }^{\prime}\end{array}$

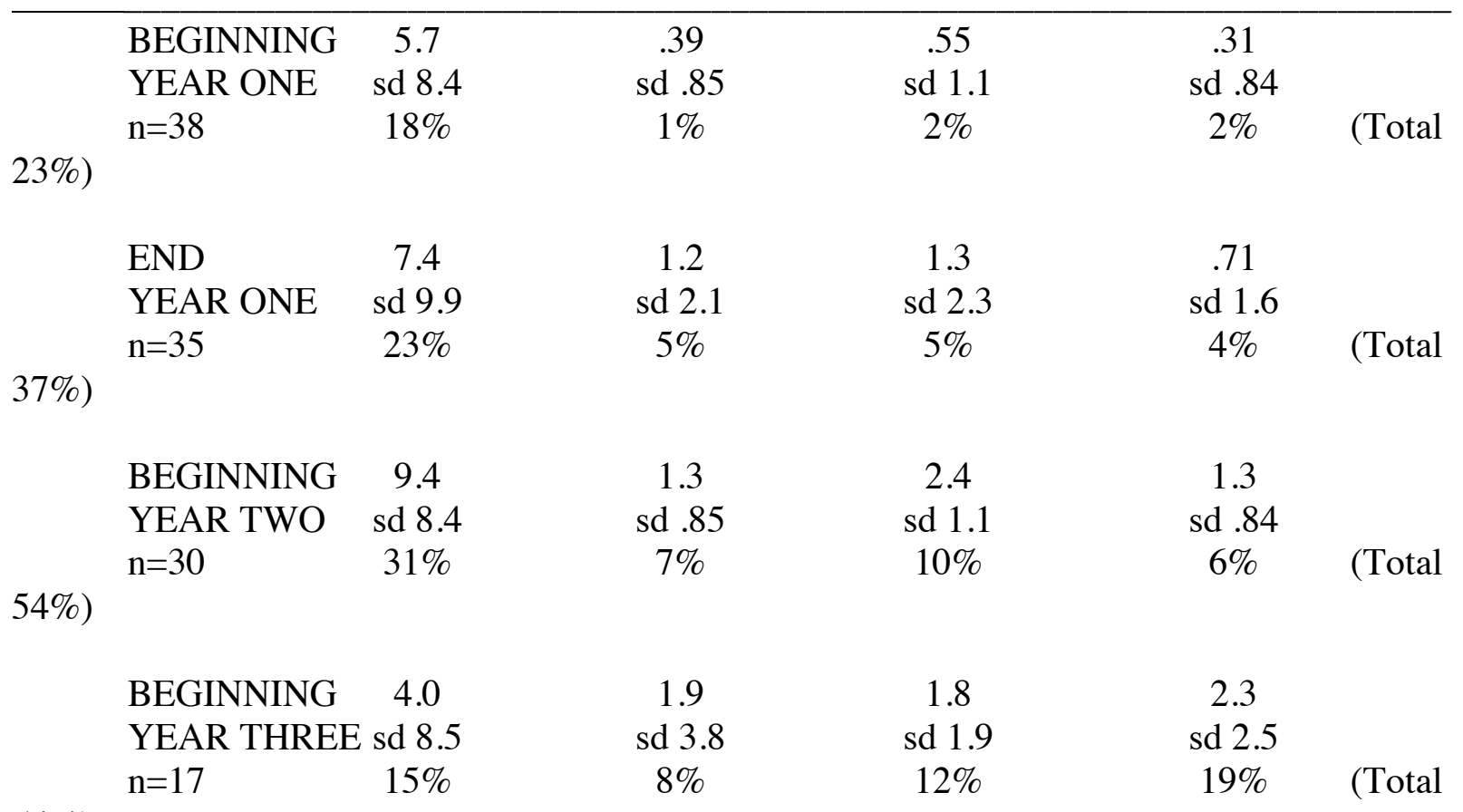

$54 \%)$

* This sample includes only those children with five or more spelling errors

** For a complete description of each error category in terms of the early development of spelling see text

***the percentage figure reflects the mean percent of the child's total errors that were made in this category.

Mean number of items correct on EXPLICIT SEGMENTATION at each testing time

\begin{tabular}{lcccc} 
& $\begin{array}{c}\text { INITIAL } \\
\text { 'k-at' }\end{array}$ & $\begin{array}{c}\text { FINAL } \\
\text { 'ka-t' }\end{array}$ & $\begin{array}{c}\text { COMPLETE } \\
\text { 'k-a-t' }\end{array}$ & TOTAL \\
\hline BEGINNING & 2.6 & .78 & 1.8 & 5.3 \\
YEAR ONE & sd 4.6 & sd 2.8 & sd 4.2 & sd 8.9 \\
END & 7.0 & 1.4 & 5.0 & 13.6 \\
YEAR ONE & sd 6.7 & sd 3.0 & sd 6.1 & sd 13.8 \\
BEGINNING & 11.3 & 3.3 & 9.0 & 23.7
\end{tabular}




\begin{tabular}{|c|c|c|c|c|}
\hline YEAR TWO & $\operatorname{sd} 5.7$ & $\operatorname{sd} 5.6$ & sd 5.5 & sd 14.0 \\
\hline \multicolumn{5}{|c|}{ Mean number of items correct on IMPLICIT SEGMENTATION at each testing time } \\
\hline & INITIAL & FINAL & MEDIAL & TOTAL \\
\hline BEGINNING & 3.0 & 3.8 & 4.4 & 11.10 \\
\hline YEAR ONE & sd 1.6 & sd 2.0 & sd 2.0 & $\mathrm{sd} 4.2$ \\
\hline END & 3.6 & 4.11 & 4.0 & 12.0 \\
\hline YEAR ONE & sd 1.8 & sd 1.5 & $\operatorname{sd} 2.2$ & sd 4.0 \\
\hline BEGINNING & 4.6 & 4.3 & 5.1 & 14.14 \\
\hline YEAR TWO & sd 2.2 & sd 2.1 & sd 2.4 & sd 5.6 \\
\hline
\end{tabular}




\section{Table 4}

\section{CORRELATIONS BETWEEN PHONEMIC AWARENESS AND LEVEL OF SPELLING DEVELOPMENT WITHIN EACH TESTING TIME} (LEVEL OF SPELLING DEVELOPMENT AS REFLECTED BY CATEGORY OF ERROR)

\section{BEGINNING 1ST YEAR}

\section{CATEGORIES OF SPELLING ERROR}

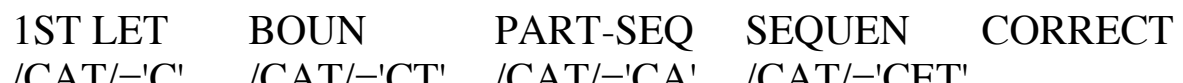
$/ \mathrm{CAT} /=^{\prime} \mathrm{C}^{\prime} \quad / \mathrm{CAT} /=^{\prime} \mathrm{CT}^{\prime} \quad / \mathrm{CAT} /=^{\prime} \mathrm{CA}^{\prime} \quad / \mathrm{CAT} /=^{\prime} \mathrm{CET}^{\prime}$

\begin{tabular}{llllll}
\hline EXP(IN) & ns & $\begin{array}{l}41 * * \\
\mathrm{~ns}\end{array}$ & $\begin{array}{l}48 * * \\
\mathrm{~ns}\end{array}$ & $\begin{array}{l}54 * * \\
\mathrm{~ns}\end{array}$ & $\begin{array}{l}64 * * \\
\mathrm{~ns}\end{array}$ \\
\hline EXP(FN) & $\mathrm{ns}$ & $31 * *$ & $\mathrm{~ns}$ & $\mathrm{~ns}$ & $32 *$ \\
$\mathrm{IMP}(\mathrm{FN})$ & $\mathrm{ns}$ & $\mathrm{ns}$ & $\mathrm{ns}$ & $\mathrm{ns}$ & $\mathrm{ns}$ \\
\hline EXP(COM) & $\mathrm{ns}$ & $\mathrm{ns}$ & $40 * *$ & $30 *$ & $40 * *$ \\
$\mathrm{IMP}(\mathrm{MED})$ & $\mathrm{ns}$ & $\mathrm{ns}$ & $\mathrm{ns}$ & $27 *$ & $\mathrm{~ns}$ \\
\hline EXP(TOT) & $\mathrm{ns}$ & $35 * *$ & $45 * *$ & $48 * *$ & $58 * *$ \\
IMP(TOT) & $\mathrm{ns}$ & $\mathrm{ns}$ & $\mathrm{ns}$ & $27 *$ & $29 *$ \\
\hline
\end{tabular}

END 1ST YEAR

$\begin{array}{llll}\text { 1ST LET } & \text { BOUN } & \text { PART-SEQ } & \text { SEQUEN CORRECT } \\ / \mathrm{CAT} /=^{\prime} \mathrm{C}^{\prime} & / \mathrm{CAT} /=^{\prime} \mathrm{CT}^{\prime} & / \mathrm{CAT} /=^{\prime} \mathrm{CA}^{\prime} & / \mathrm{CAT} /=^{\prime} \mathrm{CET}{ }^{\prime}\end{array}$

\begin{tabular}{|c|c|c|c|c|c|}
\hline EXP(IN) & ns & $29 *$ & $52 * *$ & $55 * *$ & $70 * *$ \\
\hline IMP(IN) & ns & ns & ns & $43 * *$ & $38 * *$ \\
\hline $\mathrm{EXP}(\mathrm{FN})$ & ns & $28 * *$ & ns & ns & $\mathrm{ns}$ \\
\hline $\mathrm{IMP}(\mathrm{FN})$ & ns & $29 * *$ & ns & $28 *$ & $28 *$ \\
\hline$\overline{\mathrm{EXP}(\mathrm{COM})}$ & ns & $37 * *$ & $47 * *$ & $50 * *$ & $60 * *$ \\
\hline IMP(MED) & ns & ns & ns & ns & $30 *$ \\
\hline EXP(TOT) & $\mathrm{ns}$ & $40 * *$ & $54 * *$ & $48 * *$ & $65 * *$ \\
\hline IMP(TOT) & ns & $32 *$ & ns & $47 *$ & $48 * *$ \\
\hline
\end{tabular}

\section{BEGINNING 2ND YEAR}

1ST LET BOUN PART-SEQ SEQUEN CORRECT

$/ \mathrm{CAT} /=\mathrm{C}^{\prime} \quad / \mathrm{CAT} /=\mathrm{CT}^{\prime} \quad / \mathrm{CAT} /=\mathrm{CA}^{\prime} \quad / \mathrm{CAT} /={ }^{\prime} \mathrm{CET}{ }^{\prime}$

\begin{tabular}{llllll}
\hline $\operatorname{EXP}(\mathrm{IN})$ & $\mathrm{ns}$ & $\mathrm{ns}$ & $45 * *$ & $\mathrm{~ns}$ & $61 * *$ \\
$\mathrm{IMP}(\mathrm{IN})$ & $\mathrm{ns}$ & $\mathrm{ns}$ & $\mathrm{ns}$ & $42 * *$ & $64 * *$ \\
\hline $\operatorname{EXP}(\mathrm{FN})$ & $\mathrm{ns}$ & $35 *$ & $\mathrm{~ns}$ & $29 *$ & $50 * *$
\end{tabular}


Spelling and Learning to Read. 42

\begin{tabular}{llllll}
$\mathrm{IMP}(\mathrm{FN})$ & $\mathrm{ns}$ & $\mathrm{ns}$ & $\mathrm{ns}$ & $\mathrm{ns}$ & $36 *$ \\
\hline $\mathrm{EXP}(\mathrm{COM})$ & $\mathrm{ns}$ & $\mathrm{ns}$ & $31 *$ & $\mathrm{~ns}$ & $68 * *$ \\
$\mathrm{IMP}(\mathrm{MED})$ & $\mathrm{ns}$ & $\mathrm{ns}$ & $\mathrm{ns}$ & $\mathrm{ns}$ & $\mathrm{ns}$ \\
\hline $\mathrm{EXP}(\mathrm{TOT})$ & $\mathrm{ns}$ & $\mathrm{ns}$ & $39 * *$ & $\mathrm{~ns}$ & $77 * *$ \\
$\mathrm{IMP}(\mathrm{TOT})$ & $\mathrm{ns}$ & $\mathrm{ns}$ & $\mathrm{ns}$ & $39 * *$ & $52 * *$ \\
\hline
\end{tabular}

* $\quad$ significant at $\mathrm{p}<.05$

$* * \quad$ significant at $\mathrm{p}<.01$ 